\title{
Australian Journal of

\section{Assessment of allelopathic activity of Swietenia mahagoni (L.) seed extracts on different plant species}

\author{
Krishna Rany Das ${ }^{1,2^{*}}$, Hisashi Kato-Noguchi ${ }^{1}$ \\ ${ }^{1}$ Department of Applied Biological Science, Faculty of Agriculture, Kagawa University, Miki, Kagawa 761-0795, Japan \\ ${ }^{2}$ The United Graduate School of Agricultural Sciences, Ehime University, 3-5-7 Tarumi, Matsuyama, Ehime 790-8566, \\ Japan
}

\section{*Corresponding author: k_das007@yahoo.com}

\begin{abstract}
The seeds of Swietenia mahagoni L. (Meliaceae) have been used as a traditional medicine for a long time. However, there is no report on its allelopathic activity. Considering allelopathy as an ecologically sound weed management approach, the aqueous methanol extracts of $S$. mahagoni seeds were examined on seedling growth of four dicotyledonous plants; cress, alfalfa, rapeseed, lettuce, and three monocotyledonous plants; barnyard grass, timothy and foxtail fescue at six concentrations $(0.001,0.003,0.01$, $0.03,0.1$ and $0.3 \mathrm{~g}$ dry weight (DW) equivalent extract $/ \mathrm{mL}$ ). The powder of $S$. mahagoni seeds was extracted with aqueous methanol, filtered and evaporated completely. The crude extract was then diluted with methanol to prepare six concentrations. The seeds of test plants were incubated for $48 \mathrm{~h}$ and the shoot and root length was measured. The suppression activity of $S$. mahagoni seed extracts was concentration-dependent and species-specific. For $50 \%$ inhibition $\left(I_{50}\right)$ of shoot and root growth of monocotyledonous plants, the required concentrations ranged from 0.0433-0.1443 and 0.0007-0.0348 g DW equivalent extract $/ \mathrm{mL}$, respectively. In case of dicotyledonous plants, $I_{50}$ values for the growth of shoot and root ranged from 0.0040-0.1077 and 0.0010-0.0248 g DW equivalent extract $/ \mathrm{mL}$, respectively. Considering $I_{50}$ values, the shoot growth of cress and the root growth of barnyard grass were the most sensitive, whereas foxtail fescue is found the least sensitive to the seed extracts of $S$. mahagoni. These findings suggest that the seed extracts of $S$. mahagoni may possess growth inhibitory substances and; therefore, might have possibility to be used in the biological weed management option.
\end{abstract}

Keywords: Allelopathy; aqueous methanol extracts; biological weed management; Mahogany; Meliaceae. Abbreviations: DW- dry weight; $I_{50}$-concentration required for $50 \%$ inhibition.

\section{Introduction}

From the beginning of agriculture, crop loss is caused by many kinds of pests, plant pathogens, harmful insects, and weeds. Among these pests, weeds are the most important barriers to crop production. They always have a deleterious effect on crops and cause about $34 \%$ yield losses of crops (Pitelli, 1985; Jabran et al., 2015). As weed causes significant loss on crop yields and quality, proper management of weed is an important and reclaim task in agriculture (Beveridge and Naylor, 1999; Davies and Welsh, 2002). To manage weeds, the growers mostly depend on synthetic herbicides due to their availability and quick action (Aktar et al., 2009). But indiscriminate use of herbicides now possesses a conceivable risk both to human beings and the environment (Mazumder, 2011; Daniel et al., 2013). Furthermore, the residues of pesticides have also been discerning in human breast milk, which has effects on prenatal exposure and children health (Pirsaheb et al., 2015).

Now, it is the most important to find for alternative weed management practices to mitigate the problems of synthetic herbicides. Natural products based alternative management options rather than the use of synthetic chemicals might be helpful to control weeds in sustainable agriculture (Khanh et al., 2007). In this regard, allelopathy may play an important role, in which allelopathic substances (allelochemicals) are released from one plant and affect negatively to the growth of surrounding plants (Rice, 1984). This phenomenon has encouraged researchers to search for eco-friendly management of weeds in a sustainable way (Farooq et al., 2011). The allelopathic research has mainly focused on reduction of herbicides use, perceived the allelopathic effects towards agricultural production and equipped an effective method for sustainable crop production in ecological arrangement (Macias et al., 2007; Li et al., 2010; Han et al., 2013; Jabran et al., 2015).

To explore allelopathic activity, medicinal plants have drawn attention to the researchers to find out growth inhibitory substances to control weeds (Gilani et al., 2010). Swietenia mahagoni (L.), a large perennial tree belonging to the family Meliaceae, produces good quality timber and mainly cultivated in tropical area such as in India, Malaysia and Southern China (Mulholland et al., 2000). The plant is commonly known as mahogany and deciduous in nature. The brown coloured capsules (fruits) of $S$. mahagoni are known as sky fruits, consists of numerous winged seeds. 
When the fruits become matured, the shell become split into sections and the seeds are dispersed to the ground and surrounding areas. The seeds have been used as folk medicine for the treatments of diabetes, hypertension and malaria for a long time (Nagalakshmi et al., 2001). In India and Indonesia, the seeds of S. mahagoni were used as traditional medicine to treat diabetes (Joshi et al., 2000). $S$. mahagoni seeds have also been reported to have antimutagenecity, antitumour and anti-inflammatory activities (Guevara et al., 1996). Although the medicinal uses of $S$. mahagoni have been recognised, there is no scientific report available on the allelopathic activities of this plant. Therefore, this study was conducted to assess the allelopathic activity of the seeds of $S$. mahagoni on some crops and weed species.

\section{Results}

\section{Effects of seed extracts of S. mahagoni on the shoot growth} of test plant species

The inhibitory effects of seed extracts of S. mahagoni on the growth of shoot of test species were shown in Fig 1. and Fig 2. The extracts of $S$. mahagoni seeds significantly inhibited the shoot growth of all test species. At the concentration of $0.1 \mathrm{~g} \mathrm{DW}$ equivalent extract $/ \mathrm{mL}$, the shoot growth of lettuce was significantly inhibited by $23.6 \%$ of control. At the same concentration, the shoot growth of other test species such as cress, alfalfa, rapeseed, barnyard grass, timothy and foxtail fescue were also significantly inhibited by 29.0, 35.7, $52.9,37.8,53.0$ and $63.2 \%$ of control, respectively (Fig 2.). At the concentration of $0.3 \mathrm{~g} \mathrm{DW}$ equivalent extract $/ \mathrm{mL}$, the shoot growth of lettuce, rapeseed, alfalfa, cress, barnyard grass, timothy and foxtail fescue were inhibited significantly by $5.3,9.1,9.5,12.1,12.9,21.7$ and $23.6 \%$ of control, respectively (Fig 2.). The correlation coefficient $(r)$ between shoot growth and concentration of seed extracts ranged from -0.840 to -0.971 (Table 1 ). The $I_{50}$ values for the growth of shoots of test species were ranged from 0.0040 to 0.1443 g DW equivalent extract/mL (Table 2).

\section{Effects of seed extracts of S. mahagoni on the root growth of test plant species}

The seed extracts of $S$. mahagoni significantly inhibited the root growth of the test species. Inhibition also depended on extract concentrations (Fig 1. and Fig 3.). The root growth of lettuce was completely inhibited at the concentration of 0.3 $\mathrm{g}$ DW equivalent extract $/ \mathrm{mL}$. At the same concentration, the root growth of cress, alfalfa, rapeseed, barnyard grass, timothy and foxtail fescue were significantly inhibited by 2.7 , 8.9, 6.1, 3.0, 7.1 and $12.7 \%$, respectively, compared to control (Fig 3.). As shown in Fig 3, the root growth of barnyard grass inhibited mostly (5.0\% of control) followed by cress, lettuce, timothy, rapeseed, foxtail fescue and alfalfa $(6.6,10.2,14.3,17.0,25.4$ and $36.8 \%$ of control respectively) at the concentration of $0.1 \mathrm{~g}$ DW equivalent extract $/ \mathrm{mL}$. At this concentration, significant inhibition was found in all test species except alfalfa. There was a negative correlation between the concentration of seed extracts and the root length of all test plant species and the $r$ values ranged from -0.542 to -0.878 (Table 1 ). The $I_{50}$ values of seed extracts of $S$. mahagoni for the root growth of test species ranged from 0.0007 to $0.0348 \mathrm{~g}$ DW equivalent extract $/ \mathrm{mL}$ (Table 2).

\section{Discussion}

The seeds of S. mahagoni have been reported for its therapeutic value. This is because of containing tetranortriterpenoids and fatty acids which is considered as bioactive compounds (Bacsal et al., 1997). Sahagal et al. (2009) reported the presence of several phytochemicals such as alkaloids, anthraquinones, cardiac glycosides, terpenoids, and saponins in the seeds of S. mahagoni. They also tested the crude methanolic seed extracts of $S$. mahogoni for antimicrobial activity and found that the seed extracts of $S$. mahogoni possess activity against some microorganisms. In this study, we evaluated the allelopathic activity of the aqueous methanol seed extracts of $S$. mahagoni on other plant species and found prominent growth inhibition of the test species.

The seed extracts of S. mahagoni had inhibitory effects on the shoot and root growth of both dicotyledonous and monocotyledonous plant species. The seeds of all tested species in this experiment were kept only with the extracts of $S$. mahagoni seeds and incubated in dark chamber. Thus, seedlings were not influenced by any other nutrient media or any environmental factors. So, the inhibitory activity on test plant species might be due to the existence of growth inhibitory substances presence in the seeds of $S$. mahagoni. The growth retarding activity of plant extracts containing phytotoxic substances was also reported in previous studies (Ma et al., 2011; Islam and Kato-Noguchi, 2016b).

Results obtained in this study depicted that the growth inhibition of seedlings was increased with the increases of extracts concentrations (Fig 2. and Fig 3.). This may simply because of the greater amount of inhibitory substances present in the concentrated extracts and well agreed with the findings of Sarkar et al. (2012). In line with our results, several researchers also reported similar findings of concentration dependent activity of plant extracts having allelopathic potential (Einhellig, 1996; Batlang et al., 2007; Ashrafi et al., 2008; Hassan et al., 2012; Salhi et al., 2012). Among the tested species, the shoot growth of rapeseed, barnyard grass and foxtail fescue as well as the root growth of alfalfa seedlings increased to some extent at low concentrations ( $\leq 0.03 \mathrm{~g}$ DW equivalent extract $/ \mathrm{mL}$ ) of $S$. mahagoni seed extracts though the increments were statistically insignificant $(P>0.05)$. The enhanced amylase activity might be one of the reasons that played a pivotal role in this phenomenon as the enhancing activity of amylase has been reported at low concentrations of chemicals (Singh et al., 2009).

In consideration of $I_{50}$ values, the shoot growth of cress was the most sensitive to the extracts, whereas the shoot growth of foxtail fescue was the least sensitive. In case of $I_{50}$ values for the root growth, barnyard grass showed the most sensitive and foxtail fescue was the least sensitive. Such a species-dependent response also reported by Chon et al. (2005). They found that lettuce plant had different allelopathic potentiality on alfalfa and barnyard grass. Different species, varieties and types of plant having different genetic makeup may be responsible for species 
Table 1. Correlation coefficient between the concentrations of $S$. mahagoni seed extracts and the seedling growth of the test plant species.

\begin{tabular}{lll}
\hline \multirow{2}{*}{ Test plants species } & \multicolumn{2}{c}{ Correlation coefficient $(r)$} \\
\cline { 2 - 3 } & Shoot & Root \\
\hline Cress & $-0.893^{*}$ & -0.542 \\
Alfalfa & $-0.849^{*}$ & $-0.824^{*}$ \\
Rapeseed & $-0.899^{*}$ & -0.725 \\
Lettuce & $-0.889^{*}$ & $-0.835^{*}$ \\
Barnyard grass & $-0.840^{*}$ & -0.550 \\
Timothy & $-0.948^{* *}$ & -0.757 \\
Foxtail fescue & $-0.971^{* *}$ & $-0.878^{*}$ \\
\hline Asterisks indicate statistical significance: ${ }^{*} p<0.05 ;{ }^{* *} p<0.01$. &
\end{tabular}

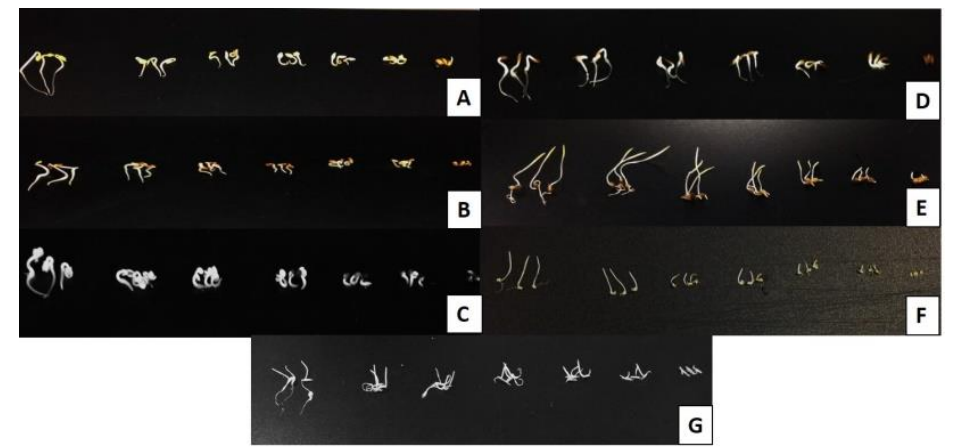

Fig 1. Effects of aqueous methanol extracts of Swietenia mahagoni seeds on the seedlings growth of cress (A), alfalfa (B), rapeseed $(C)$, lettuce $(D)$, barnyard grass $(E)$, timothy $(F)$ and foxtail fescue $(G)$. Treatment concentrations (from left to right in each test species): control, $0.001,0.003,0.01,0.03,0.1$ and $0.3 \mathrm{~g}$ dry weight equivalent extract $/ \mathrm{mL}$.

Table 2. The concentrations required for $50 \%$ inhibition ( $I_{50}$ value) on the shoot and root growth of the test plant species.

\begin{tabular}{lcc}
\hline Test plants species & $\mathrm{I}_{50}$ values (g DW equivalent extract/mL) \\
\cline { 2 - 3 } & Shoot & Root \\
\hline Cress & 0.0040 & 0.0011 \\
Alfalfa & 0.0111 & 0.0225 \\
Rapeseed & 0.1077 & 0.0010 \\
Lettuce & 0.0363 & 0.0248 \\
Barnyard grass & 0.0433 & 0.0007 \\
Timothy & 0.1087 & 0.0009 \\
Foxtail fescue & 0.1443 & 0.0348 \\
\hline
\end{tabular}

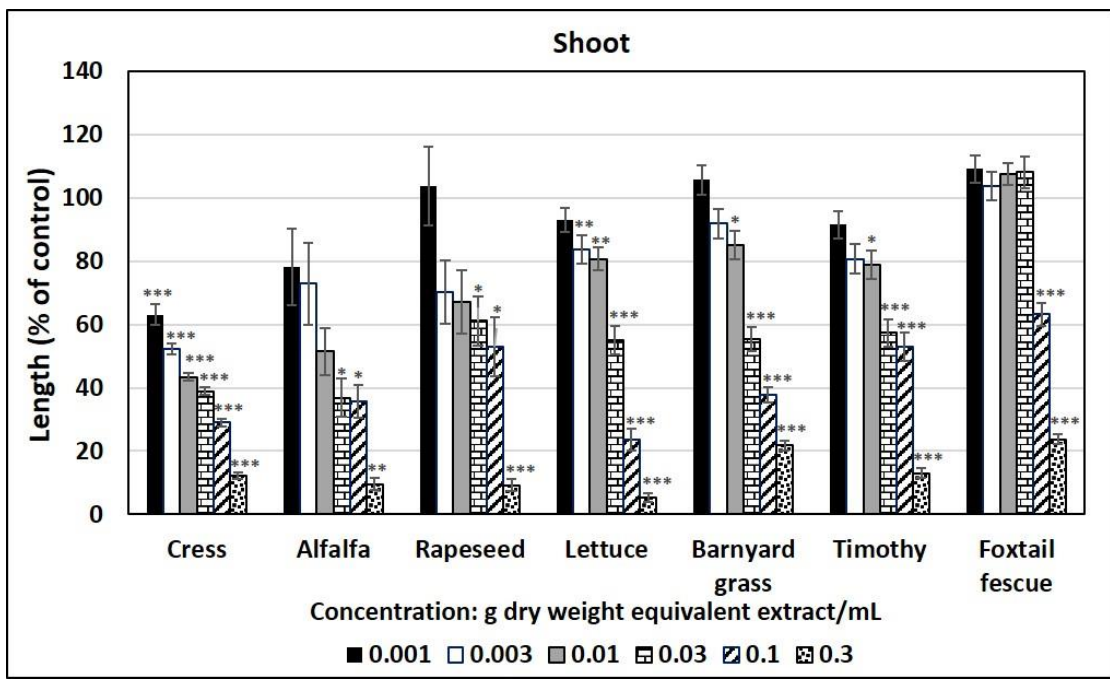

Fig 2. Effects of aqueous methanol extracts of Swietenia mahagoni seeds on the shoot growth of seven (7) test plant species. Mean \pm SE from two independent experiment with 3 replicates for each treatment are shown (seedlings per treatment $=10, n=60$ ). Significant differences between treatments and control are denoted by asterisks. ${ }^{*} p<0.05,{ }^{* *} p<0.01$ and ${ }^{* * *} p<0.001$ (One-way ANOVA, post hoc by LSD test). 


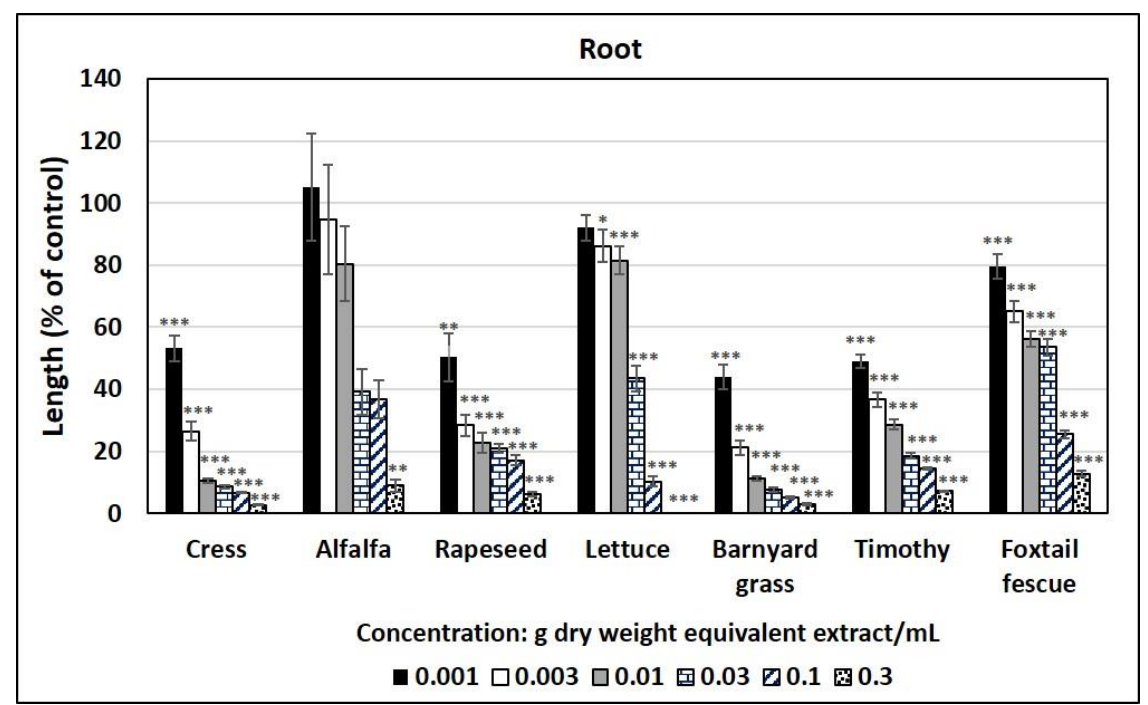

Fig 3. Effects of aqueous methanol extracts of Swietenia mahagoni seeds on the root growth of seven (7) test plant species. Mean \pm SE from two independent experiment with 3 replicates for each treatment are shown (seedlings per treatment $=10, n=60$ ). Significant differences between treatments and control are denoted by asterisks. ${ }^{*} p<0.05,{ }^{* *} p<0.01$ and ${ }^{* * *} p<0.001$ (One-way ANOVA, post hoc by LSD test).

specific inhibitory effect (Rashed Mohasel et al., 2009; Prati and Bossdorf, 2004).

Results obtained in this study clearly indicate that the inhibitory effects of seed extracts of $S$. mahagoni on the growth of roots of test species were more than the growth of shoots except alfalfa. This is in agreement with the findings of Chon et al. (2000), Amoo et al. (2008), Islam and Kato-Noguchi (2016a), Akpan et al. (2017). The potential reason behind more sensitivity of the roots may be hampering the normal cell division process in the expansion point of roots by inhibitory substances (Levizou et al., 2002). Although S. mahagoni is a timber yielding plant grown in many Asian countries, it produces considerable amount of seeds which are dispersed in the surrounding areas rendering no economical uses. In securing food selfsufficiency for the overgrowing population in developing countries like Bangladesh, farmers use pesticides indiscriminately to prevent yield losses caused by weed infestation, which create toxicity to human health and environment (Rahman, 2013; Miah et al., 2014). To minimize such harmful effects of using synthetic pesticides, biocontrol method could be an environmental friendly alternative for controlling weed infestation. In this regard, seeds of $S$. mahagoni could be a potential source for commercial production of bio-pesticides which demands further detail studies, though its seeds have demonstrated inhibitory properties on some weed species. Moreover, seeds of $S$. mahagoni are easily available in some countries like Bangladesh either at low cost or sometimes without any cost. Therefore, besides the traditional uses of $S$. mahagoni seed for medicinal purposes, it could open a new horizon for the uses in weed management, the most hurdle barrier to crop production.

\section{Materials and Methods}

\section{Collections of plant materials}

The seeds of Swietenia mahagoni L. were bought from the town market of sadar upazilla under Mymensingh district in
Bangladesh in August, 2016. Thereafter, the seeds were cleaned properly to discard the inert materials and dried in shade condition. The dried seeds were then ground into the powder and stored in polybags at $2^{\circ} \mathrm{C}$ until the use for extraction.

\section{Test plant species}

In this research, four dicotyledonous plants; cress (Lepidium sativum L.), alfalfa (Medicago sativa L.), rapeseed (Brassica napus L.), lettuce (Lactuca sativa L.), and three monocotyledonous plants; barnyard grass (Echinochloa cruss-galli L.), timothy (Phleum pratense L.) and foxtail fescue (Vulpia myuros (L.) C.C.Gmel.) were taken as test species for biological assay. Among the test species, alfalfa, cress, lettuce, rapeseed and timothy were selected as these are the model plants for laboratory bioassay having known seedling growth characteristics and sensitivity to allelopathic substances (Bich et al., 2012; Xuan et al., 2005). On the contrary, barnyard grass and foxtail fescue were selected for their weedy characters in the cultivated fields ubiquitously (Islam and Kato-Noguchi, 2013).

\section{Extraction procedure}

The powder of dry seeds (100 g) of S. mahagoni was extracted with $1500 \mathrm{~mL}$ of $70 \%(\mathrm{v} / \mathrm{v})$ aqueous methanol for $48 \mathrm{~h}$. Using one layer of filter paper (No. 2; $125 \mathrm{~mm}$, Advantec Toyo Roshi Kaisha, Ltd.,Tokyo, Japan), filtration was done with the vacuum pump. The residue was extracted once more with equal volume of methanol for $24 \mathrm{~h}$ and filtered. Two filtrates were saturated together and then evaporated with a rotary evaporator at $40^{\circ} \mathrm{C}$ before coming complete dryness.

\section{Growth bioassay}

The crude extract of S. mahagoni was diluted in $300 \mathrm{~mL}$ of methanol to prepare six assay concentrations $(0.001,0.003$, $0.01,0.03,0.1$ and $0.3 \mathrm{~g} \mathrm{DW}$ equivalent extract $/ \mathrm{mL}$ ). An 
aliquot part of the extracted sample diluted in methanol was added to a sheet of filter paper (No. 2; $28 \mathrm{~mm}$, Toyo.) in 28 $\mathrm{mm}$ diameter petri dishes. In a draft chamber, methanol was evaporated. Then $0.6 \mathrm{~mL}$ of $0.05 \%(\mathrm{v} / \mathrm{v})$ aqueous solution of polyoxyethylene sorbitan monolaurate (Tween 20; Nacalai Tescue, Inc., Kyoto, Japan) was added on the filter paper in the Petri dishes. Tween 20 was used as a nontoxic surfactant for the growth of seedlings of all test species. Ten seeds of cress, alfalfa, rapeseed and lettuce were placed in the petri dishes. On the other hand, ten pre-emergence seeds of barnyard grass, timothy and foxtail fescue (germinated in the darkness at $25^{\circ} \mathrm{C}$ for $72 \mathrm{~h}, 73 \mathrm{~h}$ and $48 \mathrm{~h}$ respectively, after overnight soaking in distilled water) arranged on the filter paper in the petri dishes. Control seeds or seedlings were also sown on the filter paper in the petri dishes without plant extracts but moistened with $0.6 \mathrm{~mL}$ of $0.05 \%$ $(\mathrm{v} / \mathrm{v})$ aqueous solution of Tween 20 . Then the shoot and root length of the seedlings were measured after $48 \mathrm{~h}$ incubation in a growth chamber at $25^{\circ} \mathrm{C}$. With reference to the length of control seedlings, percentage length of the seedlings was calculated. The required concentrations for $50 \%$ growth suppression $\left(I_{50}\right)$ in the assay of the test species were calculated by a logistic regression equation of the concentration-response curves.

\section{Statistical analysis}

All bioassay experiments were conducted as completely randomized design (CRD) with three replicates and repeated twice using 10 seedlings. Using SPSS software (version 16.0, IBM Corp. 2007), experimental data were analysed. The data generated in each experiment were subjected to analysis of variance (ANOVA) and the significant differences between the mean of treatments and control were determined by post-hoc analysis with LSD test at $5 \%$ level of probability. To analyse the correlation of coefficient $(r)$ between extract concentrations and seedlings growth of test plant species, Two-tailed Pearson Correlation test was used (by SPSS version 16.0). The $I_{50}$ value of the test species in the assay were analysed by GraphPad Prism 6.0 (GraphPad Software, Inc., La Jolla, California, USA).

\section{Conclusion}

In conclusion, the aqueous methanol seed extracts of $S$. mahagoni exhibited inhibitory effects on the seedling growth of test species. The inhibition was found concentration-dependent and species-specific. These findings suggest that the extracts of seeds of $S$. mahagoni possess growth inhibitory substances, which may be responsible for the inhibition of plant growth. Therefore, the seeds of S. mahagoni could be served as a conceivable candidate for the isolation and characterization of inhibitory substances, which may open a new insight in the management of noxious weeds over the commonly practice method of using synthetic chemicals.

\section{Acknowledgements}

The authors would like to acknowledge The Ministry of Education, Culture, Sports, Science and Technology (MEXT), Japan for providing financial support through the scholarship to Krishna Rany Das for conducting this study.

\section{References}

Akpan EN, Denise EM, Ezendiokwelu EL, Anyadike MC (2017) Growth response of seedlings of Zea mays (L.) to aqueous extract of Lycopodium clavatum (L.). MOJ Biol Med. 2(4):00058.

Aktar MW, Sengupta D, Chowdhury A (2009) Impact of pesticides use in agriculture: their benefits and hazards. Interdisc Toxicol. 2:1-12.

Amoo SO, Ojo AU, Van SJ (2008) Allelopathic potential of Tetrapleura tetraptera leaf extracts on early seedling growth of five agricultural crops. S Afr J Bot. 74:149-152.

Ashrafi ZY, Sadeghi S, Mashhadi HR, Hassan MA (2008) Allelopathic effects of sunflower (Helianthus annuus) on germination and growth of wild barley (Hordeum spontaneum). J Agric Technol. 4:219-229.

Bacsal K, Chavez L, Diaz I, Espina S, Javillo J, Manzanilla H, Motalban J, Panganiban C, Rodriguez A, Sumpaico C, Talip B, Yap S (1997) The effect of Swietenia mahagoni (mahogany) seed extract on indomethacin-induced gastric ulcers in female sprague- dawley rats. Acta Medica Philippina. 3:127-139.

Batlang U, Shushu DD (2007) Allelopathic activity of sunflower (Helianthus annus L.) on growth and nodulation of bambara groundnut (Vigna subterranean L. Verdc.). J Agron. 6:541-547.

Beveridge LE, Naylor REL (1999) Options for organic weed control- what farmers do. In: Proceedings of the 1999 Brighton Crop Protection Conference-Weeds. 3:939-944.

Bich TTN, Kato-Noguchi H (2012) Allelopathic potential of two aquatic plants, duckweed (Lemna minor L.) and water lettuce (Pistia stratiotes L.) on terrestrial plant species. Aquat Bot. 103:30-36.

Chon SU, Coutts JH, Nelson CJ (2000) Effects of light, growth media and seedling orientation on bioassays of alfalfa autotoxicity. Agron J. 92:715-720.

Chon SU, Jang HG, Kim DK, Kim YM, Boo HO, Kim YJ (2005) Allelopathic potential in lettuce (Lactuca sativa L.) plants. Sci Hort. 106:309-317.

Daniel M, Duniya N, Adams IG (2013) Effect of continuous application of herbicide on soil and environment with crop protection machinery in southern Adamawa state. Int Referd J Eng Sci. 2(6):4-9.

Davies DHK, Welsh JP (2002) Weed control in organic cereals and pulses. pp:77-144. Younie, D., B. R. Taylor and J. M. Wilkinson (eds). Chalcombe publications, Lincoln.

Einhellig FA (1996) Mechanism of action of allelochemicals in allelopathy. Agron J. 88:886-893.

Farooq M, Jabran K, Cheema ZA, Wahid A, Siddique KHM (2011) The role of allelopathy in agricultural pest management. Pest Manage Sci. 67:494-506.

Gilani SA, Fujii Y, Shinwari ZK, Adnan M, Kikuchi A, Watanabe KN (2010) Phytotoxic studies of medicinal plant species of Pakistan. Pak J Bot. 42(2):987-996.

Guevara AP, Apilado A, Sakurai H, Kozuka M, Tokuda H (1996) Anti-inflammatory, antimutagenic and antitumor promoting activities of mahogany seeds, Swietenia macrophylla (Meliaceae). Philipp J Sci. 125:271-278.

Han X, Cheng ZH, Meng HW, Yang XL, Ahmad I (2013) Allelopathic effect of decomposed garlic (Allium sativum L.) stalk on lettuce (L. sativa Var. crispa L.). Pak J Bot. 45:225-233. 
Hassan MH, Daffalla HM, Yagoub SO, Osman MG, Gani MEA, Babiker AEGG (2012) Allelopathic effects of some botanical extracts on germination and seedling growth of Sorghum biocolor L. J Agril Tech. 8(4):1423-1469.

Islam AKMM, Kato-Noguchi H (2013) Plant growth inhibitory activity of medicinal plant Hyptis suaveolens: could alleloipathy be a cause? Emir J Food Agric. 25:692-701.

Islam MS, Kato-Noguchi H (2016a) Allelopathic potential of the weed Fimbristylis dichotoma (L.) on four dicotyledonous and four monocotyledonous test plant species. Res On Crops. 17(2):388-394.

Islam MS, Kato-Noguchi H (2016b) Phytotoxicity assessment of Cyperus difformis (L.) towards a sustainable weed management option. J Anim Plant Sci. 26(6):1765-1771.

Jabran K, Mahajan G, Sardana V, Chauhan BS (2015) Allelopathy for weed control in agricultural systems. Crop Prot. 72:57-65.

Joshi S (2000) Medicinal plants. Oxford and IBH Publishing Co. Pvt. Ltd., New Delhi, India.

Khanh TD, Elzaawely AA, Chung IM, Ahn JK, Tawata S, Xuan TD (2007) Role of allelochemical for weed management in rice. Allelopathy J. 19:85-96.

Levizou E, Karageorgou P, Psaras GK, Manetas Y (2002) Inhibitory effects of water soluble leaf leachates from Dittrichia viscosa on lettuce root growth, statocyte development and graviperception. Flora. 197:152-157.

Li ZH, Wang Q, Ruan X, Pan CD, Jiang DA (2010) Phenolics and plant allelopathy. Molecules. 15:8933-8952.

Ma L, Wu H, Bai R, Zhou L, Yuan X, Hou D (2011) Phytotoxic effects of Stellera chamaejasme L. root extract. Afr J Agric Res. 6(5):1170-1176.

Macias FA, Molinillo JM, Varela RM, Galindo JC (2007) Allelopathy - a natural alternative for weed control. Pest Manage Sci. 63:327-348.

Mazumder B (2011) A study on the harmful effects of pesticides used in the cultivation of brinjal in longai river valley, Karimganj, Assam, India. Assam Univ J Sci Tech.: Biol Env Sci. 7(1):84-88.

Miah SJ, Hoque A, Paul A, Rahman A (2014) Unsafe use of pesticide and its impact on health of farmers: a case study in Burichong upazila, Bangladesh. J Env Sci Toxicol Food Tech. 8(1):57-67.
Mulholland DA, Parel B, Coombes P, Curr H (2000) The chemistry of the Meliaceae and Ptaeroxylaceae of southern and eastern Africa and Madagascar. J Org Chem. 4: 1011-1054.

Nagalakshmi MAH, Thangadurai D, Muralidara D, Pullaiah RT (2001) Phytochemical and antimicrobial study of Chukrasia tabularis leaves. Fitoterapia. 72:62-64.

Pirsaheb M, Limoee M, Namdari F, Khamutian R (2015) Organochlorine pesticides residue in breast milk: a systematic review. Med J Islam Repub Iran. 29:228.

Pitelli RA (1985) Interferência de plantas daninhas em culturas agrícolas. Inf Agropec. 120: 16-27.

Prati D, Bossdorf O (2004) Allelopathic inhibition of germination by Alliaria petiolata (Brassicaceae). Am J Bot. 91:285-288.

Rahman S (2013) Pesticide consumption and productivity and the potential of IPM in Bangladesh. Sci Total Environ. 445-446:48-56.

Rashed Mohasel MH, Qarakhloo J, Rastgoo M (2009) Allelopathic effect of safran (Crocus sativus) leaf extract on redroot pigweed and common goosefoot. Iranian J Crop Res. 7(1):53-61.

Rice EL (1984) Allelopathy. 2nd ed. London: Academic press. Sahagal G, Ramanathan S, Sasidharan S, Mordi MN, Ismail S, Mansor SM (2009) Phytochemical and antimicrobial activity of Swietenia mahagoni crude methanolic seed extract. Trop Biomed. 26(3):274-279.

Salhi N, El-Darier SM, Halilat MT (2012) The allelochemicals effect of Zygophyllum album on control of Bromus tectorum. J Life Sci. 6:182-186.

Sarkar E, Chatterjee SN, Chakraborty P (2012) Allelopathic effect of Cassia tora on seed germination and growth of mustard. Turk J Bot. 36:488-494.

Singh A, Singh D, Singh N (2009) Allelochemical stress produced by aqueous leachate of Nicotiana plumbaginifolia Viv. Plant Growth Regul. 58:163-171.

Xuan TD, Tawata S, Khanh TD, Chung IM (2005) Biological control of weeds and plant pathogens in paddy rice by exploiting plant allelopathy: an overview. Crop Prot. 24: 197-206. 